\title{
A PROSPECTIVE SURVEY OF APPROPRIATENESS OF PAIN PHARMACOTHERAPY MANAGEMENT IN POST-CESAREAN SECTION PATIENTS IN CIPTO MANGUNKUSUMO HOSPITAL
}

\author{
JOHAN $^{1}$, INSTIATY ${ }^{1}$, NAFRIALDI ${ }^{1 *}$, YUDITIYA PURWOSUNU ${ }^{2}$ \\ ${ }^{1}$ Department of Pharmacology and Therapeutics, Faculty of Medicine, Universitas Indonesia, Jakarta 10430, Indonesia. ${ }^{2}$ Department of \\ Obstetrics and Gynecology, Faculty of Medicine, Universitas Indonesia, Jakarta 10430, Indonesia. Email: nafrialdi@gmail.com
}

Received: 13 September 2018, Revised and Accepted: 27 February 2019

\section{ABSTRACT}

Objective: In this study, we sought to assess the pattern of analgesic usage, adequacy of pain management, side effects, and analgesic drug interactions in the post-emergency cesarean surgery setting.

Methods: This was a prospective observational study of 80 patients who underwent emergency cesarean surgery at the Obstetrics and Gynecology Department of the Rumah Sakit Umum Pusat Nasional Cipto Mangunkusumo (RSUPN-CM) between July 2015 and January 2016. Adequacy of pain management during the first 3 post-operative days was assessed using Pain Management Index. Relation between pain intensity during activities and rest with patient characteristic was assessed using Chi-squared test and Fischer's exact test.

Results: Nineteen patients (8.7\%) were prescribed two types of nonsteroid anti-inflammatory drugs concomitantly, and $41.8 \%$ received inappropriate analgesics at a lower frequency. Most patients experienced pain with numerical rating scale score $>3$ in the first 24 h post-surgery: 59 patients (73.75\%) experienced pain during activities and 7 patients (8.75\%) during rest.

Conclusion: Post-emergency cesarean surgery pain management at RSUPN-CM was not optimal. Most patients did not receive adequate pain management in the first $24 \mathrm{~h}$ post-surgery.

Keywords: Pain management, Emergency cesarean surgery, Numerical rating scale.

(c) 2019 The Authors. Published by Innovare Academic Sciences Pvt Ltd. This is an open access article under the CC BY license (http://creativecommons. org/licenses/by/4. 0/) DOI: http://dx.doi.org/10.22159/ijap.2019.v11s1.032

\section{INTRODUCTION}

Fear of post-surgery pain is a major concern of patients scheduled for surgery. The International Association for the Study of Pain defines pain as a bad sensory and emotional experience related to tissue injury. Uncontrolled post-surgical pain is known to induce physiologic and clinical changes that are associated with increased mortality and morbidity, increased treatment cost, and decreased quality of life [1]. In a survey conducted in a hospital in Ethiopia, only $19.9 \%$ of surgical patients received adequate therapy for post-surgical pain [2].

Post-surgical pain is a complex problem. Therefore, several factors need to be considered during administration of analgesics such as the optimal analgesic combination, dosage, interaction of analgesics with other drugs, adverse effects, and treatment cost. In this prospective study, we sought to assess the pattern of analgesic usage (type, dosage, frequency, and mode of administration) and pain management, side effects, and analgesic drug interactions in the post-emergency cesarean surgery setting.

\section{METHODS}

Study design and subjects

This was a prospective observational study of female patients who had undergone emergency cesarean surgery at the Obstetrics and Gynecological Department of the Rumah Sakit Umum Pusat Nasional Cipto Mangunkusumo (RSUPN-CM) between July 2015 and January 2016. Consecutive sampling technique was employed in this study. Patients who received analgesics post-emergency cesarean surgery and provided written informed consent for participation in the study were enrolled. Patients with altered sensorium, and mental or cognitive disorders, those who received epidural analgesic therapy after cesarean surgery, and patients with oncological or gynecologic disorders were excluded from the study. Adequacy of pain management was assessed by Pain Management Index (PMI). Analgesic prescription was categorized as 0 (no use of analgesic), 1 (non-opioid), 2 (low-dose opioid), and 3 (high-dose opioid). PMI was calculated by decreasing the analgesic score with the score given based on reported pain. PMI ranged from -3 (patient in severe pain but did not use analgesic) to +3 (patients were administered high-dose opioids and reported no pain). Negative PMI showed that analgesic therapy was inadequate, whereas positive PMI (score $>0$ ) showed that analgesic therapy was adequate.

\section{Data collection}

Data were collected from medical records and by interview of subjects. Data pertaining to demographic characteristics (name, age, date of visit, and medical record number), laboratory results, diagnosis, duration of surgery, and analgesic usage (type, dosage, prescription, and frequency) were extracted from the medical records.

Pain intensity was assessed by numerical rating scale (NRS) and was categorized as no pain (NRS score: 0 ), mild pain (NRS score: $1-3$ ), moderate pain (NRS score: 4-7), and severe pain (NRS score: 8-10). Assessment of pain was done for 3 days, i.e., at 24,48 , and $72 \mathrm{~h}$ after surgery.

\section{Study ethics}

This research protocol was approved by the FK UI/RSCM Research Ethics Committee (No. 465/UN2.F1/ETIK/2015).

\section{Statistical analysis}

Statistical analysis was performed using SPSS 20 versus. Patient characteristics, pain intensity, and analgesic usage (type, frequency, accuracy of drug prescription, and drug prescription) were assessed by descriptive analysis. Association between pain intensity and patient characteristics was assessed using Chi-squared test and Fisher's exact test. 


\section{RESULTS}

A total of 92 patients underwent cesarean surgery at the RSUPN-CM during the study reference period. Of these, 80 patients were included in this study. One patient was discharged; therefore, the total number of subjects on day 2 was 79. Total patients analyzed on day 3 were 60 . All patients in this study underwent cesarean surgery under spinal anesthesia with bupivacaine $0.5 \%(12.5 \mathrm{mg})$ plus fentanyl $(25 \mathrm{mcg})$. A majority of patients in this study $(71.25 \%)$ were unemployed, $88.75 \%$ were covered by National Health Insurance, and $82.5 \%$ of patients had not undergone prior cesarean surgery (Table 1).

Total number of analgesics and accuracy of usage based on dosage About $87.5 \%$ of patients received one type of analgesic during the first $24 \mathrm{~h}$ during 3 days of treatment, 19 patients (8.7\%) were administered two analgesics (nonsteroidal anti-inflammatory drug [NSAID]+NSAID) simultaneously, whereas 2 patients $(0.9 \%)$ were administered NSAID+low-dose opioid (tramadol) (Table 2). During 3 days of treatment, the analgesic dosage prescribed was generally correct. Subtherapeutic dosage was prescribed in patients who received two analgesics, i.e., tramadol for 2 days of treatment.

\section{Analgesic prescription frequency}

The most frequently prescribed analgesic frequency on the $1^{\text {st }}$ day of treatment was thrice a day (60\%), whereas 6 patients $(7.5 \%)$ were given analgesic just once a day (Table 2). In the first $24 \mathrm{~h}, 12$ patients were administered more than one type of analgesic, whereas one

\section{Table 1: Characteristics of the study population}

\begin{tabular}{|c|c|c|}
\hline Characteristic & Total & $\%$ \\
\hline \multicolumn{3}{|l|}{ Occupation } \\
\hline Unemployed & 57 & 71.25 \\
\hline Employed & 23 & 28.75 \\
\hline \multicolumn{3}{|l|}{ Fee system } \\
\hline National health insurance & 71 & 88.75 \\
\hline Private & 9 & 11.25 \\
\hline \multicolumn{3}{|l|}{ Pregnancy status } \\
\hline Primigravida & 27 & 33.75 \\
\hline Multigravida & 53 & 66.25 \\
\hline \multicolumn{3}{|l|}{ Age (years) } \\
\hline$<30$ & 41 & 51.25 \\
\hline$\geq 30$ & 39 & 48.75 \\
\hline \multicolumn{3}{|l|}{ Educational level } \\
\hline$\leq$ Middle school & 25 & 31.25 \\
\hline$\geq$ High school & 55 & 68.75 \\
\hline \multicolumn{3}{|l|}{ History of previous surgery } \\
\hline Yes & 14 & 17.5 \\
\hline No & 66 & 82.5 \\
\hline \multicolumn{3}{|l|}{ Duration of surgery } \\
\hline$\leq 60 \min$ & 54 & 67.5 \\
\hline$>60 \min$ & 26 & 32.5 \\
\hline \multicolumn{3}{|l|}{ Ethnicity } \\
\hline Javanese & 38 & 47.5 \\
\hline Batavianese & 29 & 36.25 \\
\hline Others* & 13 & 16.25 \\
\hline \multicolumn{3}{|l|}{ Indication for emergency cesarean surgery } \\
\hline Premature rupture of membranes & 36 & 45 \\
\hline Severe preeclampsia-eclampsia & 17 & 21.25 \\
\hline Others $\#$ & 27 & 33.75 \\
\hline \multicolumn{3}{|l|}{ Perioperative analgesics } \\
\hline Paracetamol 1 g IV & 35 & 43.75 \\
\hline Paracetamol 1 g IV+Tramadol 100 mg IV & 35 & 43.75 \\
\hline Paracetamol 1 g IV+Tramadol 50 mg IV & 1 & 1.25 \\
\hline Paracetamol 1 gr IV+Dexketroprofen 50 mg IV & 1 & 1.25 \\
\hline Paracetamol 1 gr IV+Ketorolac 30 mg IV & 4 & 5 \\
\hline Ketorolac $30 \mathrm{mg}$ IV & 1 & 1.25 \\
\hline Tramadol 100 mg IV & 3 & 3.75 \\
\hline Total & 80 & \\
\hline
\end{tabular}

*Sumateranese, Ambonnese, and Kupangnese, "Antepartum bleeding,

fetal distress, intrauterine growth restriction, Kala I opening, atonia uteri,

intrauterine infection, cephalopelvic disproportion, HIV, transverse lie fetus patient was not administered any analgesic. Of 67 patients who were administered only one type of analgesic during the first $24 \mathrm{~h}, 41.8 \%$ received inappropriate analgesic and at a lower frequency than that recommended by the guidelines.

\section{Mode of administration}

The most commonly used mode of analgesic administration on day 1 and day 2 was as rectal suppository ( $81.25 \%$ and $32.91 \%$, respectively). The percentage of patients who were administered oral analgesics increased from day $1(1.25 \%)$ to day 3 (43.33\%). A similar pattern was observed with respect to percentage of patients who did not receive analgesic (1.25\% on day 1 and $46.67 \%$ on day 3 ) (Table 2 ).

\section{Pain intensity}

The intensity of pain experienced during activities showed a decreasing trend; $66.25 \%$ of patients felt moderate pain on day 1 as against $5 \%$ on day 3 . On day $1,73.75 \%$ of patients experienced pain with NRS score $>3$. The same pattern was observed with respect to pain intensity during rest; $8.75 \%$ of patients felt moderate pain on day 1 as against $0 \%$ on day 3. On day $1,8.75 \%$ of patients experienced pain with NRS score $>3$ (Fig. 1). (Table 3) shows that perioperative analgesics used, paracetamol alone or incombination with tramadol, have significant influence on pain intensity during activity (p: 0.016 ), but not during relax.

\section{Adequacy of pain management}

The adequacy of pain management was assessed using PMI. A total of $59(73.75 \%)$ patients were inadequately treated (PMI score was minus). NRS scores during activities on day 1 were included in the calculation of PMI.

\section{Side effects of analgesics and their interactions}

Ten of the 80 patients experienced side effects such as nausea and dizziness. On the basis of the Naranjo Adverse Drug Reaction Probability Scale, these symptoms were likely caused by NSAIDs. Only one patient experienced nausea, which was likely attributable to ketoprofen.

Potential analgesic interactions were observed on day 3. Of the 32 analgesics used on day 3, potential drug interactions of two drugs (ketoprofen and sodium diclofenac) with bisoprolol were observed.

Relation between pain intensity control and patient characteristics There was no significant association of pain intensity control during activities or rest in the first $24 \mathrm{~h}$ treatment with a history of the previous cesarean surgery, duration of surgery, age of patients, educational level,

Table 2: Characteristics of analgesic prescription

\begin{tabular}{|c|c|c|c|}
\hline \multirow[t]{2}{*}{ Parameters } & Day-1 & Day-2 & Day-3 \\
\hline & n (\%) & n (\%) & n (\%) \\
\hline \multicolumn{4}{|l|}{ Type of analgesics } \\
\hline One type of analgesic & $70(87.5)$ & $51(64.56)$ & $30(50)$ \\
\hline \multicolumn{4}{|l|}{ Combination of analgesics } \\
\hline NSAID+NSAID & $9(11.25)$ & $8(10.13)$ & $2(3.33)$ \\
\hline NSAID+low-dose opioid & - & $2(2.53)$ & - \\
\hline No use of analgesic & $1(1.25)$ & $18(22.78)$ & $28(46.67)$ \\
\hline \multicolumn{4}{|l|}{ Frequency } \\
\hline Once a day & $6(7.5)$ & $30(37.98)$ & 17 (28.33) \\
\hline Twice a day & $24(30)$ & $16(20.25)$ & $9(15)$ \\
\hline Thrice a day & $48(60)$ & $14(17.72)$ & $5(8.33)$ \\
\hline 4 times a day & $1(1.25)$ & $1(1.27)$ & $1(1.67)$ \\
\hline No use of analgesic & $1(1.25)$ & $18(22.78)$ & $28(46.67)$ \\
\hline \multicolumn{4}{|l|}{ Mode of administration } \\
\hline Rectal suppository & $65(81.25)$ & $26(32.91)$ & $3(5)$ \\
\hline Rectal suppository+oral & $11(13.75)$ & $15(18.99)$ & $3(5)$ \\
\hline Suppository+IV & $2(2.5)$ & $0(0)$ & $0(0)$ \\
\hline Oral & $1(1.25)$ & $20(25.32)$ & $26(43.33)$ \\
\hline No use of analgesic & $1(1.25)$ & $18(22.78)$ & $28(46.67)$ \\
\hline Total & $80(100)$ & $79(100)$ & $60(100)$ \\
\hline
\end{tabular}


Table 3: Relationship between pain intensity control and patient characteristics

\begin{tabular}{|c|c|c|c|c|c|c|}
\hline \multirow[t]{2}{*}{ Parameters } & \multicolumn{2}{|c|}{ Pain intensity during activities } & \multirow[t]{2}{*}{ p-value } & \multicolumn{2}{|c|}{ Pain intensity during relax } & \multirow[t]{2}{*}{ p-value } \\
\hline & Uncontrolled (NRS >3) & Controlled (NRS $\leq 3$ ) & & Uncontrolled & Controlled & \\
\hline \multicolumn{7}{|l|}{ History of cesarean surgery } \\
\hline No & 50 & 16 & $0.504^{\#}$ & 6 & 60 & $1.000^{\#}$ \\
\hline Yes & 9 & 5 & & 1 & 13 & \\
\hline \multicolumn{7}{|l|}{ Duration of surgery } \\
\hline$>60 \mathrm{~min}$ & 20 & 6 & $0.654^{*}$ & 3 & 23 & $0.676^{\#}$ \\
\hline$\leq 60 \min$ & 39 & 15 & & 4 & 50 & \\
\hline \multicolumn{7}{|l|}{ Age } \\
\hline$\geq 30$ years & 29 & 10 & $0.904^{*}$ & 3 & 36 & $1.000^{\#}$ \\
\hline$<30$ years & 30 & 11 & & 4 & 37 & \\
\hline \multicolumn{7}{|l|}{ Educational level } \\
\hline$\leq \mathrm{SLTP}$ & 16 & 9 & $0.181^{*}$ & 0 & 25 & $0.092^{\#}$ \\
\hline$\geq$ SLTA & 43 & 12 & & 7 & 48 & \\
\hline \multicolumn{7}{|l|}{ Perioperative analgesics } \\
\hline PCT 1 gr IV & 21 & 14 & $0.016^{\#}$ & 2 & 33 & $0.673^{\#}$ \\
\hline PCT 1 gr+Tramadol 100 mg IV & 30 & 5 & & 4 & 31 & \\
\hline Inappropriate & 19 & 9 & & & & \\
\hline Appropriate & 29 & 10 & $0.560^{*}$ & & & \\
\hline
\end{tabular}

${ }^{*}$ Chi-squared, "Fisher's exact test; $\mathrm{p}<0.05$, PCT: Paracetamol

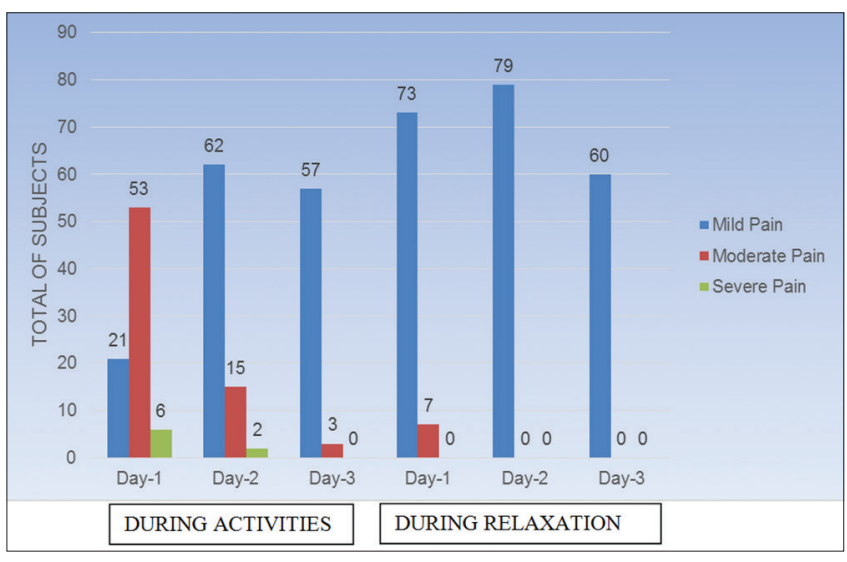

Fig. 1: Pain intensity during activities and relaxation

and adequacy of analgesic prescription frequency. The proportion of patients with controlled pain among those who received perioperative paracetamol $1 \mathrm{~g}$ IV was higher than that among patients who received perioperative paracetamol $1 \mathrm{~g}+$ tramadol $100 \mathrm{mg}$ IV $(\mathrm{p}=0.016)$

\section{DISCUSSION}

In this study, most patients were prescribed NSAIDs (99.01\%), whereas two patients received tramadol as the second analgesic. Similar results were reported from an online survey by Tagaloa et al. conducted through the members of Society of Obstetric Anesthesia and Perinatology; the results showed that $81 \%$ of patients were administered NSAIDs for pain management post-cesarean surgery [3]. Similarly, in a descriptive study by Tennant et al. in Jamaica, $80.3 \%$ of patients were administered NSAIDs after surgery [4].

In this study, 19 patients (8.7\%) were prescribed two types of NSAIDs simultaneously with a similar frequency of administration. This result is lower than that reported from a prescription pattern survey in Pakistan (2014) in which $60 \%$ of patients were prescribed a combination of two types of NSAIDs [5]. Due to similar mechanism of action and other pharmacodynamic considerations, the NSAID+NSAID combination is not recommended according to the WHO conceptual framework of analgesic ladder for post-operative pain management [6]. Besides, concomitant use of more than one type of NSAIDs increases the risk of toxicity and peptic ulcer [7]. A pharmacovigilance study in France (2004) showed that the use of two types of NSAIDs increases the risk of gastrointestinal bleeding, disorder of liver function, and acute kidney disease [8].

In this study, $28(41.8 \%)$ patients received less than the recommended frequency of analgesics on day 1. Guidelines from the American Pain Society recommend analgesic prescription based on schedule in the early period after surgery, especially during the first $24 \mathrm{~h}$, to prevent and control pain [9]. In addition, guidelines from the American Society of Anesthesiologists (2004) also recommend the use of NSAIDs, COX-2 inhibitors, or acetaminophen based on schedule in all patients in the absence of any contraindications [10]. On the basis of these guidelines, the prescription frequency was inadequate in $41.8 \%$ of patients and $73.75 \%$ of patients felt severe pain during the $24 \mathrm{~h}$ after surgery; therefore, the pain management was not optimal.

On day 1 and day 2, most patients (81.25\% and 32.91\%, respectively) were administered analgesic through rectal suppository, and on day 3,3 patients $(5 \%)$ were administered analgesic through suppository. Oral route was shown to be better than the parenteral route for administration of NSAIDs for post-operative pain management [11]. Oral prescription is easier to administer, safe, and cheap [12]. Intramuscular and rectal administration is associated with local side effects, and parenteral administration is associated with a high risk of bleeding. Most doctors still prescribe NSAIDs through parenteral route even if the patients can consume through oral route; this is largely attributable to pharmacokinetic considerations because parenteral administration is associated with faster onset of action [13]. If paracetamol, with or without NSAID, is not adequate in relieving pain, administration of short-term tramadol could be considered. However, this drug should be avoided in patient with high risk of convulsion, such as severe preeclampsia, since tramadol decreases convulsion threshold and might elcite seizure [14].

This study showed that most patients during treatment experienced pain during activities (NRS score $>3$ ). On day 1,59 patients $(73.75 \%)$ still experienced pain with NRS score $>3$, which decreased to $17(21.52 \%)$ patients and $3(5 \%)$ patients on day 2 and day 3 . These findings differ from those reported by Ismail et al.; in their study, $39.9 \%$ of patients experienced moderate-severe pain during activities. This difference may be attributable to the fact that in their study, $94 \%$ of patients were prescribed opioids through parenteral infusion (pethidine/tramadol/ morphine) and $74.8 \%$ of patients received additional sodium diclofenac rectal suppository (100 mg) twice a day [15].

On the basis of pain targets of the Joint Commission on Accreditation, pain score should not be $>3$ during rest or activities. The Royal College 
of Anaesthetists recommends that $>90 \%$ of females should have post-operative visual analog scale score of 0-3 [16]. Therefore, the management of pain after emergency cesarean surgery in our study population was not optimal as $73.75 \%$ of patients still felt pain during activities (NRS score $>3$ ) and 7 patients $(8.75 \%)$ still felt pain during rest (NRS score $>3$ ).

On the basis of the PMI method, 59 (73.75\%) patients did not receive adequate pain management. Similar results were reported by Shen et al. from China; in their study, $60.2 \%$ of post-surgery patients were treated inadequately, as assessed by PMI [17]. In a survey conducted in a hospital in Ethiopia, 80.1\% of post-surgery patients received inadequate treatment to manage post-surgery pain [2]. Inadequacy of pain management based on PMI depends on prescription or the use of opioids because it could lead to negative PMI scores.

The number of patients with controlled pain intensity among those who received perioperative paracetamol $1 \mathrm{~g}$ IV was higher than that among those who received paracetamol 1 g+tramadol $100 \mathrm{mg}$ IV (14 vs. 5); Fischer's exact test showed a significant difference $(p=0.016)$. This result is surprising because the latter regimen should be more effective in pain control. The discrepancy may be attributable to the variability in the use of analgesics in the operating room and the relative small sample size ( 70 patients). Further studies are required to compare the pain intensity control post-surgery with paracetamol $1 \mathrm{~g}$ IV and paracetamol $1 \mathrm{gr}+$ tramadol $100 \mathrm{mg}$ IV.

Two potential drug interactions (ketoprofen and sodium diclofenac with bisoprolol [beta-blocker]) were observed in this study. Concomitant use of NSAIDs and bisoprolol may decrease the antihypertensive efficacy of bisoprolol. The use of NSAIDs may lead to increase in blood pressure and lower the antihypertensive efficacy of drugs such as diuretics, ACE inhibitors, ARB, and beta-blocker by $50 \%[18,19]$. NSAIDs inhibit prostaglandin synthesis, which act as vasodilators, both in systemic circulation and in kidneys; therefore, NSAIDs may lead to water and sodium retention and decrease the activity of renin. All these factors play a role in increasing blood pressure [20].

This study had several limitations such as variation in the use of analgesics, assessment of pain intensity $24 \mathrm{~h}$ after surgery, and the small sample size (70 patients). All these factors may have introduced an element of bias. Furthermore, the relation between pain intensity management with paracetamol $1 \mathrm{~g}$ IV prescription compared with paracetamol 1 g+tramadol $100 \mathrm{mg}$ IV should be assessed in a future study.

\section{CONCLUSION}

Post-emergency cesarean surgery pain management was not optimal. Most patients (73.75\%) did not receive adequate pain management at $24 \mathrm{~h}$ after surgery.

\section{CONFLICTS OF INTEREST}

All authors declare that they have no conflicts of interest.

\section{REFERENCES}

1. Baumann TJ, Strickland JM, Herndon CM. Pain management. In: Wells BG, editor. Pharmacotherapy a Pathophysiologic Approach. $8^{\text {th }}$ ed. United States: McGraw-Hill; 2011. p. 989.

2. Woldehaimanot TE, Eshetie TC, Kerie MW. Postoperative pain management among surgical treated patients in an Ethiopian hospital. PLoS One 2014:9:1-9.

3. Tagaloa LA, Butwick AJ, Carvalho B. A survey of perioperative and postoperative anesthetic practices for cesarean delivery. Anesthesiol Res Pract 2009;2009:1-7.

4. Tennant I, Augier R, Sykes AC, Boothe DF, Aitken NM, Jones K, et al. The Post-Operative Pain Experience and an Assessment of Analgesic Administration in Elective Surgical Patients at a Teaching Hospital in Kingston, Jamaica. Priory Lodge Education Limited; 2012. Available from: http://www.priory.com/anaesthesia/post_operative_pain.htm. [Last cited on 2018 Sep 02].

5. Gul S, Ayub M. Prevalence of prescribing pattern of more than one NSAID in Pakistan. J Sci Innov Res 2014;3:148-54.

6. UL Hospitals. Mid-Western Regional Hospitals Complex St. Camillus and St. Ita's Hospitals. Analgesic Policy; 2009. p. 5. Available from: https://www.hse.ie/eng/services/list/3/acutehospitals/hospitals/ulh/ staff/resources/pppgs/analgesicpdf. [Last cited on 2018 Sep 02].

7. Wilmana PF, Gan S. Analgesic-antipyretic analgesics for nonsteroidal anti-inflammation and other join disorders [In Indonesia] Analgesikantipiretik analgesik anti-inflamasi nonsteroid dan obat gangguan sendi lainnya. In: Gunawan S, Setaibudy R, editors. Farmakologi dan Terapi. $5^{\text {th }}$ ed. Jakarta: Gaya Baru; 2009. p. 230-41.

8. Cliard F, Sgro C, Bardou M, Hillon P, Dumas M, Kreftjais C, et al. Association between concomitant use of several systemic NSAIDs and an excess risk of adverse drug reaction. A case/non-case study from the French pharmacovigilance system database. Eur J Clin Pharmacol 2004; 60:279-83

9. Wells N, Pasero C, McCaffery M. Improving the quality of care through pain assessment and management. In: Patient Safety and Quality: An Evidence-Based Handbook for Nurses. Vol. 1. Rockville, Md: AHRQ; 2008. p. 469-97.

10. Buvanendran A, Lubenow TR, Kroin JS. Postoperative pain and its management. In: McMahon SB, Koltzenburg M, Tracey I, Turk DC, editors. Wall and Melzack Textbook of Pain. $6^{\text {th }}$ ed. Philadelphia, PA: Elsevier; 2013. p. 633

11. Cepeda MS. Overview of pain management. In: Approches to Pain Management an Essential Guide for Clinical Leader. Oakbrook, IL: Joint Commission Resources; 2003. p. 1-20.

12. Neugebauer EA. Acute pain management. Gen Surg 2009;2009:63-72.

13. Phillips DM. JCAHO pain management standards are unveiled. Joint commission on accreditation of healthcare organizations. JAMA 2000; 284:428-9

14. Palmer CM, D'angelo R, Paech MJ. Post-Cesarean Analgesia. Oxford: Oxford University Press; 2011. p. 156-81.

15. Ismail S, Shahzad K, Shafiq F. Postoperative pain management of cesarean section patient. J Anaesthesiol Clin Pharmacol 2012;28:36-40.

16. Pickering E, Holdcraft A. Pain relief after cesarean section. In: Kinsella M, editor. Raising the Standard: A Compendium of Audit Recipes. $2^{\text {nd }}$ ed. London: Royal College of Anaesthetists; 2006. p. $168-9$.

17. Shen Q, Sherwood GD, McNeill JA, Li Z. Postoperative pain management outcome in Chinese patients. West J Nurs Res 2008; 30:975-90.

18. Horn JR, Hasten PD. Coadministration of NSAIDs and antihypertensive agents. Pharmacy Times 2006;72:54.

19. Houston MC. Nonsteroidal anti-inflammatory drugs and antihypertensives. Am J Med 1991;90:42S-7.

20. Webster J. Interactions of NSAIDs with diuretics AND betablockers mechanisms and clinical implications. Drugs 1985;30:32-41. 